\title{
Focal mechanisms and stress field in the Atotsugawa fault area, central Honshu, Japan
}

\author{
Kei Katsumata ${ }^{1}$, Masahiro Kosuga ${ }^{2}$, Hiroshi Katao ${ }^{3}$, and the Japanese University Group \\ of the Joint Seismic Observations at NKTZ

\begin{abstract}
${ }^{1}$ Institute of Seismology and Volcanology, Graduate School of Science, Hokkaido University, Sapporo 060-0810, Japan ${ }^{2}$ Earthquake and Volcano Observatory, Graduate School of Science and Technology, Hirosaki University, Hirosaki 036-8561, Japan ${ }^{3}$ Research Center for Earthquake Prediction, Disaster Prevention Research Institute, Kyoto University, Uji 611-0011, Japan
\end{abstract}

(Received May 20, 2009; Revised December 17, 2009; Accepted December 21, 2009; Online published June 17, 2010)

\begin{abstract}
We have determined 151 high quality focal mechanism solutions for earthquakes that occurred between January 2005 and December 2006 in and around the Atotsugawa fault area in central Honshu, Japan. We used $P$-wave first motion polarity data observed by a dense temporary seismic observation conducted in the area by the Japanese University Group. The types of obtained focal mechanism solutions are predominantly strike-slip, however, some earthquakes exhibit reverse- and normal-fault type focal mechanisms. Without regard to faulting type, the averaged directions of compressional $(P)$ and extensional $(T)$ axes are rather uniform, $\mathrm{N} 70^{\circ} \mathrm{W}$ and $\mathrm{N} 16^{\circ} \mathrm{E}$, respectively. We found that not a small number of normal-fault type earthquakes occurred in a small cluster near the central part of Atotsugawa fault, and in a very short period from the end of March to the beginning of April in 2005. In order to estimate stress field around the fault, we applied a stress tensor inversion method to the focal mechanism solutions. Both the maximum principal stress $\left(\sigma_{1}\right)$ and the minimum principal stress $\left(\sigma_{3}\right)$ axes are almost horizontal and trend $\mathrm{N} 72^{\circ} \mathrm{W}$ to $\mathrm{N} 77^{\circ} \mathrm{W}$ and $\mathrm{N} 14^{\circ} \mathrm{E}$ to $\mathrm{N} 20^{\circ} \mathrm{E}$, respectively. The direction of $\sigma_{1}$ and the fault trace form an angle of $43^{\circ}-48^{\circ}$. It is clear that the $\sigma_{1}$ axis is neither perpendicular nor parallel to the Atotsugawa fault, indicating strong coupling of fault. The stress tensor inversion also suggests local extensional stress field at a deep $(>8 \mathrm{~km})$ central part of Atotsugawa fault. We present a hypothesis that the extensional stress is caused locally in a transition zone from the fluid-rich aseismic creep zone to the seismogenic zone that is interpreted as an asperity ruptured by the 1858 Hietsu Earthquake $(M=7.0)$.
\end{abstract}

Key words: Focal mechanism, stress tensor inversion, Atotsugawa fault, Hietsu Earthquake, creep, normal faulting.

\section{Introduction}

Recent observation by the nationwide dense GPS array (GEONET by the Geographical Survey Institute of Japan) detected a zone with high strain rate of E-W contraction in the area from Niigata to Kobe in central Japan. This zone is called the Niigata-Kobe Tectonic Zone (NKTZ) (e.g., Sagiya et al., 2000). Since not only large historic earthquakes such as 1858 Hietsu Earthquake $(M=7.0)$ but also some recent damaging earthquakes such as 2004 Mid Niigata Prefecture (Chuetsu) earthquake $\left(M_{\mathrm{W}}=6.6\right)$ and 2007 Niigataken Chuetsu-oki earthquake $\left(M_{\mathrm{W}}=6.7\right)$ took place along the zone, the tendency has grown up to reveal the relation between strain accumulation and earthquake generation in the NKTZ. Earthquakes are the strain release process by sudden slip of fault, therefore, the understanding of strain accumulation mechanisms will provide a clue to clarify the earthquake generation mechanisms. The research in the NKTZ is also expected to contribute to establish a general model of seismogenic process in the Japanese Islands.

Copyright (c) The Society of Geomagnetism and Earth, Planetary and Space Sciences (SGEPSS); The Seismological Society of Japan; The Volcanological Society of Japan; The Geodetic Society of Japan; The Japanese Society for Planetary Sciences; TERRAPUB.

doi:10.5047/eps.2009.12.006
On this background, a large-scale seismic observation was performed in the northwestern Chubu district during the period from 2004 to 2008 by the joint observation group that consist of many universities; e.g., Hokkaido University, Hirosaki University, Tohoku University, the University of Tokyo, Nagoya University, Kyoto University, Kyushu University, and Kagoshima University (The Japanese University Group of the Joint Seismic Observations at NKTZ, 2005). The 73 temporary seismic stations were deployed in an area of $100 \mathrm{~km} \times 100 \mathrm{~km}$ including the Atotsugawa fault system (Fig. 1). The seismic network consists of 63 online seismic stations with telemetry system and 10 offline stations with portable recorder. The seismic data observed by these stations were analyzed together with the data by permanent stations operated in and around the region. The combined stations form a very dense network with an average station interval of about $5 \mathrm{~km}$ or less.

The Atotsugawa fault system is one of the most prominent active fault systems in the Chubu region, central Japan, and was the main research target of the joint observation. The fault system consists of three major right-lateral strikeslip faults, the Atotsugawa, the Ushikubi, and the MozumiSukenobu faults, with a maximum length of about $80 \mathrm{~km}$ and striking ENE-WSW direction. A historical large earthquake, the 1858 Hietsu earthquake $(M=7.0)$, is consid- 


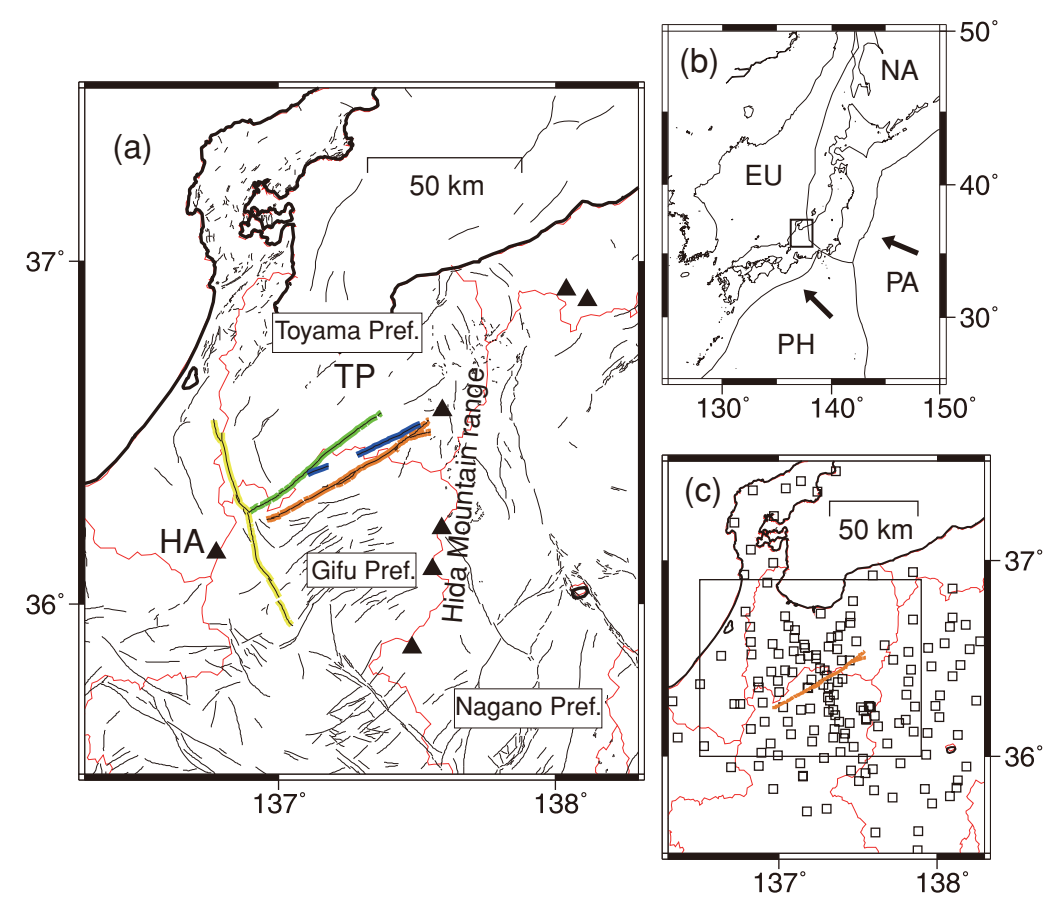

Fig. 1. Map showing Atotsugawa fault area. (a) Orange, green, yellow, and blue bold lines are the Atotsugawa, the Ushikubi, the Miboro, and the Mozumi-Sukenobu faults, respectively. Other thin lines are other active faults. Closed triangles show active volcanoes. HA: Hakusan volcano, and TP: Toyama plain. The name of prefectures are indicated in rectangles, and red lines show their boundaries. (b) The study area and the plate configuration. PA: Pacific plate, PH: Philippine Sea plate, EU: Eurasian plate, and NA: North American plate. Two arrows indicate the plate motion of PA and PH relative to EU. (c) Seismographic stations used in this study. A rectangle is an area shown in Fig. 3.

ered to be caused by the slip of Atotsugawa fault. Generally seismicity along active faults in Japan decreases to very low level long after large earthquakes, however, the present seismicity along the Atotsugawa fault system is extraordinarily high even though more than 150 years have passed from the Hietsu earthquake.

Seismicity in the Atotsugawa fault area has been investigated by many researchers (Mikumo et al., 1985, 1988; Wada and Ito, 1995; Wada et al., 2001; Ito and Wada, 2002; Ito et al., 2003). Earthquakes along the Atotsugawa and the Mozumi-Sukenobu faults form narrow vertical planes with a thickness of less than $2 \mathrm{~km}$. Focal depths along the Atotsugawa fault are deepest $(\sim 15 \mathrm{~km})$ at the middle part of fault, and decrease to about $5 \mathrm{~km}$ at both ends bounded by the Hida Mountain range to the east and the Hakusan volcano to the west. This suggests depth variations of brittleductile transition affected by higher temperature beneath the volcanoes. Shallow seismicity is relatively low in the middle part of fault. Creep movement has reported from the electro-optical distance measurements at the central part of fault (Geographical Survey Institute, 2000). Kato et al. (2007) interpreted the characteristics of shallow seismicity along the fault on the basis of fine velocity structure imaged by using both natural and artificial sources observed by a dense seismic network including the joint observation.

Earthquake focal mechanisms in the northwest Chubu (Hida) region have been studied by Mikumo et al. (1985, 1988), Koizumi et al. (1993), Wada and Ito (1995), and Wada et al. (2001, 2003). Along the Atotsugawa fault system, the $P$-axis is oriented WNW-ESE, which is consistent with the regional trend in the Chubu region. Several researchers (Mikumo et al., 1988; Koizumi et al., 1993) pointed out a systematic deviation of $P$ - and $T$-axes in the Hida Mountain ranges from the regional trend. In addition to many strike-slip type focal mechanisms in the Atotsugawa area, some events particularly in the southwestern part of fault exhibit dip-slip mechanisms having inconsistent $P$-axes with the fault movement. Thus the gross feature of spatial distribution of focal mechanisms has been grasped in the Atotsugawa fault area, however, the origin of stress heterogeneity inferred from the focal mechanisms has not yet resolved well.

The spatial variation of focal mechanisms are quite important to provide direct information concerning the stress state that should be included in a model of strain concentration and release process in the inland crust. At present focal mechanisms in the Atotsugawa fault area can be determined for small earthquakes of $M<1.5$, however, the number of focal mechanism solutions is still insufficient to picture the stress field precisely with a spatial resolution that can be compared with the fine velocity structure obtained by Kato et al. (2007). The first purpose of this paper is to obtain the precise spatial distribution of focal mechanisms in the Atotsugawa fault area using the $P$-wave first motion data collected by the joint seismic observation. The second purpose is to estimate the stress field from a set of focal mechanism data and to reveal the cause of stress heterogeneity in the area by referring to the tomographic studies.

\section{Data}

We used waveform data from the temporary seismic network operated by the Japanese University Group of the Joint Seismic Observations at NKTZ (2005) (Fig. 1). The purpose of observation was to get insight to the relation be- 


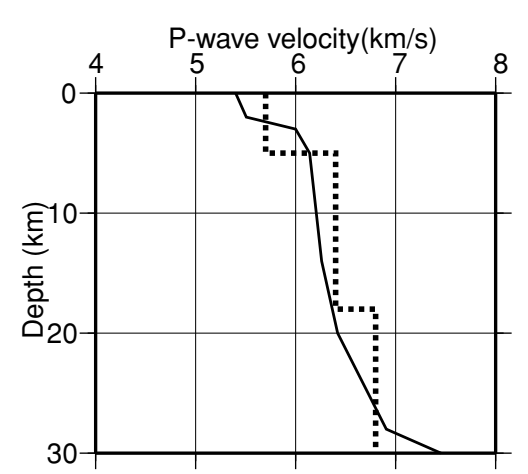

Fig. 2. $P$-wave velocity structure used for hypocenter location in the study area. Solid line indicates the structure used for the routine hypocenter determination at Kamitakara Seismic Observatory, Kyoto University (Ito and Wada, 2002). Broken line indicates the structure based on an explosion experiment (Iidaka et al., 2003).

tween strain accumulation in the NKTZ and the occurrence of large earthquakes in the Zone, by combined observation of natural and artificial earthquakes, crustal deformation, and electrical conductivity. The seismic network consisted of 63 temporary seismographic stations and 95 permanent stations. The temporary stations were concentrated in and around the Atotsugawa fault (Fig. 1). A typical seismometer at each station had three-components with a natural frequency of $1 \mathrm{~Hz}$. All waveform data were transmitted continuously by a communication satellite or the Internet connection to Kyoto University and the University of Tokyo.

We determined hypocenters by a program of HYPOMH, which is based on a simple algorithm to find the maximum likelihood solution with a Bayesian approach (Hirata and Matsu'ura, 1987). We assumed a 1-D $P$-wave velocity structure (Fig. 2) (Ito and Wada, 2002), which is the same as that used for the hypocenter calculation at the Kamitakara seismic observatory of Kyoto University (KTJ), located near the Atotsugawa fault. The $S$-wave velocity was given by the assumption of $V_{P} / V_{S}=\sqrt{3}$, where $V_{P}$ and $V_{S}$ are $P$ - and $S$-wave velocities, respectively. This assumption that is equivalent to assume the Poisson's ratio of 0.25 is applied mostly to crustal structures, while values in the mantle take typically higher Poisson's ratio (approximately 0.28 ) and so higher $V_{P} / V_{S}$ ratio (approximately 1.8).

\section{Method}

\subsection{Focal mechanism solution}

We located 657 earthquakes in the study area observed between January 2005 and December 2006 with depths shallower than $20 \mathrm{~km}$ and magnitudes ranging from -0.1 to 4.4 (Fig. 3). The earthquakes are concentrated along the Atotsugawa fault and volcanic chain that runs N-S in the eastern part of Fig. 3, while hypocenters are scattered in the northwestern part of figure. The $P$-wave first-motion polarities were picked manually with a careful inspection. To determine focal mechanism solutions we applied a program HASH to the polarity data. HASH is a FORTRAN program using a grid-search to find a set of acceptable focal mechanisms (Hardebeck and Shearer, 2002). During the process of grid search, the increment angle for strike, dip, and rake of focal mechanism solution was set to be $5^{\circ}$. The HASH

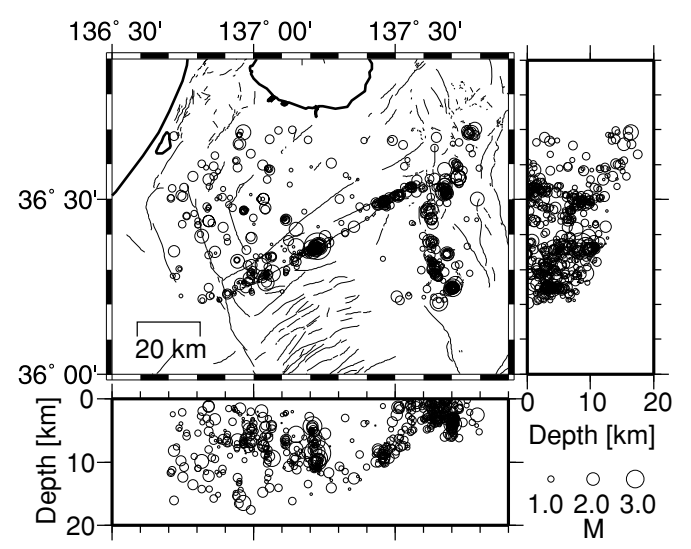

Fig. 3. Seismic activity in the study area. We located 657 events that occurred between January 2005 and December 2006.

determines a focal mechanism solution if an earthquake satisfies the following conditions associated with station coverage: (1) the number of polarity data is more than 8 , (2) the maximum azimuthal gap is smaller than $90^{\circ}$ on the focal sphere, and (3) the maximum takeoff angle gap is smaller than $60^{\circ}$. An acceptable set of solutions is selected among trial solutions computed by varying earthquake location and velocity structure. The event depth was chosen randomly from a normal distribution based on the vertical standard error reported by HYPOMH. The average horizontal and vertical errors calculated by HYPOMH were $\pm 0.2 \mathrm{~km}$ and $\pm 0.3 \mathrm{~km}$, respectively. To estimate the uncertainty of takeoff angle, we assumed the two velocity structures shown in Fig. 2. The one is the structure used at KTJ and employed in this study, and the other is that from Iidaka et al. (2003) based on a seismic explosion experiment in 2001. The spread of the acceptable mechanisms determines the uncertainty and the solution quality.

\subsection{Stress tensor inversion}

In order to produce a regional scale model of stress orientation, we applied a stress tensor inversion method to the focal mechanism solutions obtained by the HASH technique. The method used in this study is SATSI (Spatial And Temporal Stress Inversion) developed by Hardebeck and Michael (2006), which is a modified version of Michael's code (Michael, 1987). In the SATSI a study area is divided into small subareas, and a damped inversion method is applied to simultaneously invert for stress in all subareas while minimizing the difference in stress between adjacent subareas. Stress orientation uncertainty was estimated using 2000 bootstrap resampling of the entire data (Hardebeck and Michael, 2006). The 1-sigma confidence region of the stress model is defined by the $68 \%$ of bootstrap solutions closest to the preferred solution.

\section{Results}

\subsection{Focal mechanism solutions}

We determined 500 focal mechanisms in the study area. The quality of solutions determined by the HASH technique is defined by four parameters, average misfit, RMS fault plane uncertainty, station distribution ratio, and mechanism probability (Hardebeck and Shearer, 2002). The number of 

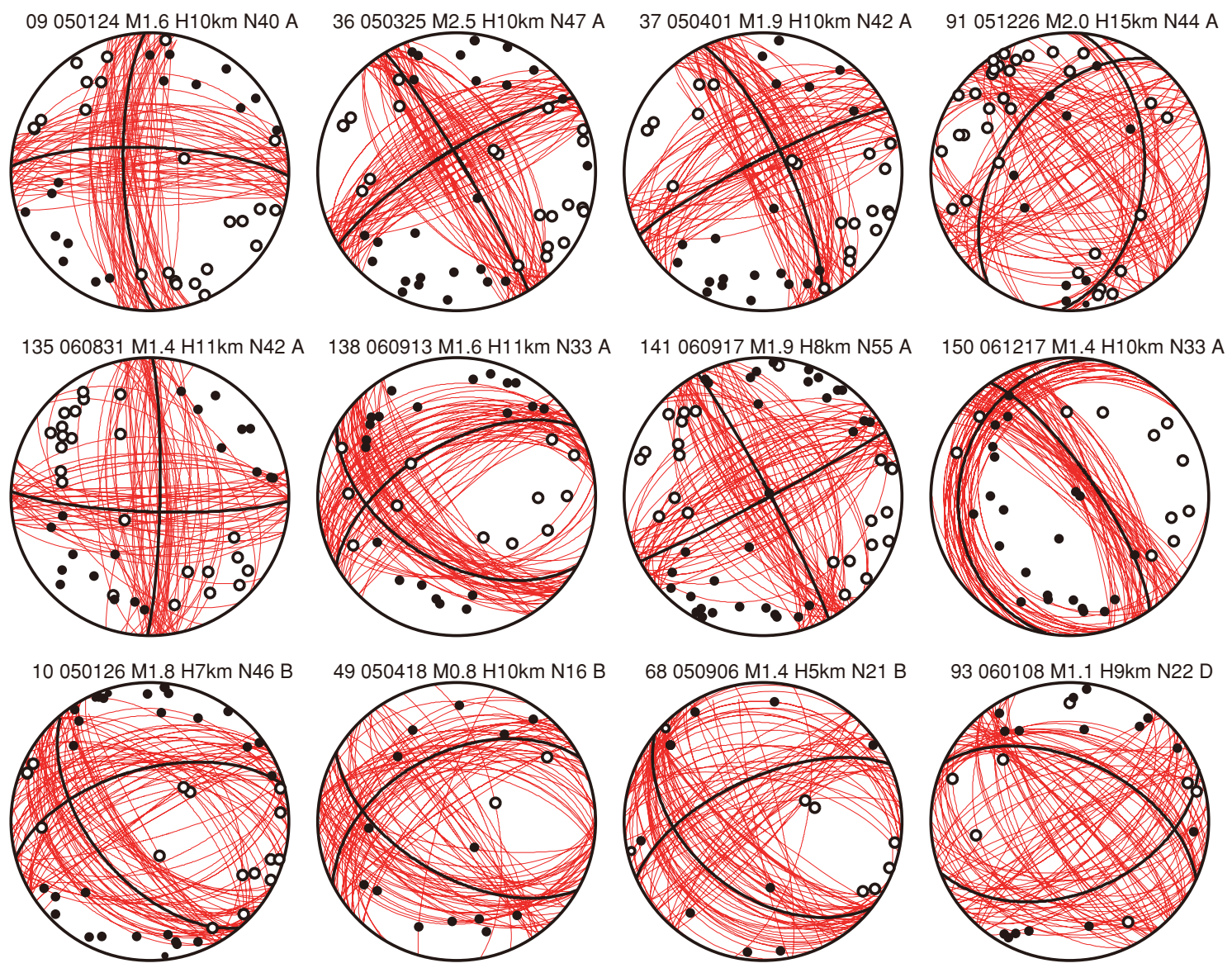

Fig. 4. Typical focal mechanism solutions in the Atotsugawa fault area. All diagrams are equal area projection on the lower hemisphere of focal sphere. Solid and open circles indicate compressional and dilatational first motions, respectively. The black lines indicate the preferred mechanisms, whereas the red lines show 50 mechanisms chosen from the set of acceptable solutions. Event number, event date, magnitude, focal depth, the number of polarity data, and quality (A-D) are shown on the top of each mechanism diagram.

solutions with Qualities A (the highest quality), B, C, and $\mathrm{D}$ (the lowest quality) was $16,49,47$, and 39 , respectively. The typical solutions with Quality A are shown in Fig. 4 (the event number 09, 36, 37, 91, 135, 138, 141, and 150) together with the acceptable mechanisms and the preferred final solution. The all 151 focal mechanism solutions with Quality A to D are plotted in Figs. 5 and 6, and listed on Table 1. The number of abandoned solutions with Quality E is 349 , which are the events that did not satisfy the conditions (2) and (3) mentioned in 3.1, indicating that the station coverage was poor. Since the depth of hypocenters in the Atotsugawa fault area is typically shallower than $10 \mathrm{~km}$, few stations are distributed near the center of focal sphere. It was necessary to set more seismic stations close to the epicenter in order to constrain the focal mechanism solution accurately, though many stations were deployed around the fault.

We obtained various types of focal mechanisms as shown in Figs. 5 and 6, however, we found that the trend of $P$ and $T$-axes is fairly uniform (Fig. 7). The average azimuths of $P$ - and $T$-axes are $\mathrm{N} 70^{\circ} \mathrm{W}$ and $\mathrm{N} 16^{\circ} \mathrm{E}$, respectively, for the all mechanisms in the study area (Fig. 7). Both the $P$ and $T$-axes have near horizontal dip angles. These facts are also clear for the earthquakes along the Atotsugawa fault (Fig. 8). The average azimuths of $P$ - and $T$-axes are approximately $\mathrm{N} 71^{\circ} \mathrm{W}$ and $\mathrm{N} 15^{\circ} \mathrm{E}$, respectively, which are al- most the same as those obtained from the 151 events in the whole study area. The direction of the surface trace of the Atotsugawa fault is approximately $\mathrm{N} 60^{\circ} \mathrm{E}$. Therefore the angle is $50^{\circ}$ between the fault trace and the average direction of $P$-axis, which is consistent with the rightlateral strike-slip displacement of the Atotsugawa fault. There is an area with high seismicity in the middle of the Atotsugawa fault trace around $36.4^{\circ} \mathrm{N}$ and $137.2^{\circ} \mathrm{E}$. We obtained 61 focal mechanisms with qualities $A$ to $D$ in this active cluster area (Fig. 9). The angle is $45^{\circ}$ between the fault trace and the average directions of both $P$ - and $T$-axes in the active cluster area, which is also consistent with the right-lateral strike-slip faulting.

\subsection{Normal faulting events}

We found that 10 earthquakes with the normal faulting $\left(-140^{\circ} \leq\right.$ rake $\left.\leq-90^{\circ}\right)$ occurred in the active cluster area. Examples of the normal faulting mechanism are shown in Fig. 4 with the event number of 10, 49, 68, and 93. The number of these earthquakes appears to increase with focal depth. The $T$-axis has nearly horizontal dip and the dip of $P$-axis is distributed from vertical to horizontal angles in the portion deeper than $\sim 8 \mathrm{~km}$. We also found that the normal faulting events were clustered in a short time period (Fig. 10). Seven of the 10 events occurred between the end of March and the beginning of April in 2005. The seven events have small magnitude ranging from 0.1 to 0.9 , and 
Table 1. Focal mechanism solutions in the Atotsugawa fault area determined in this study.

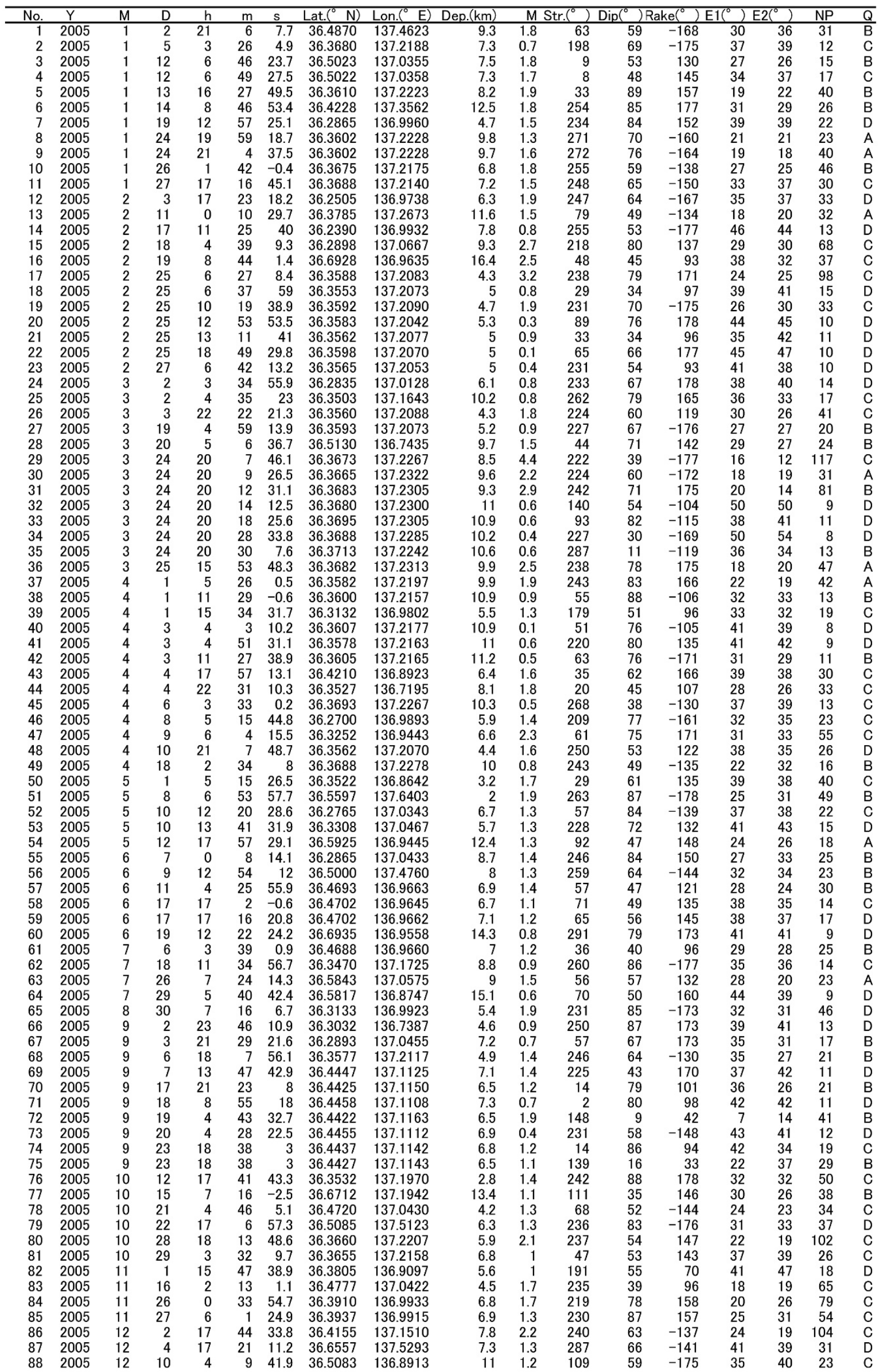


Table 1. (continued).

\begin{tabular}{|c|c|c|c|c|c|c|c|c|c|c|c|c|c|c|c|c|}
\hline 89 & 2005 & 12 & 15 & 16 & 7 & 36.7 & 36.5993 & 137.0327 & 14.7 & 1.6 & 245 & 84 & 163 & 31 & 34 & 38 \\
\hline 90 & 2005 & 12 & 21 & 5 & 56 & 19.4 & 36.2845 & 137.0337 & 2.9 & 1.5 & 203 & 72 & 163 & 29 & 30 & 56 \\
\hline 91 & 2005 & 12 & 26 & 8 & 42 & 27.4 & 36.6590 & 136.9518 & 15.3 & 2 & 216 & 49 & 112 & 13 & 13 & 44 \\
\hline 92 & 2005 & 12 & 27 & 14 & 31 & 50.3 & 36.3578 & 137.2127 & 7.7 & 1.1 & 71 & 58 & -143 & 38 & 31 & 31 \\
\hline 93 & 2006 & 1 & 8 & 11 & 20 & 51.2 & 36.3602 & 137.2207 & 9.1 & 1.1 & 68 & 47 & -126 & 37 & 41 & 22 \\
\hline 94 & 2006 & 1 & 20 & 20 & 40 & 39 & 36.4547 & 136.7648 & 5.9 & 1.1 & 245 & 58 & 94 & 32 & 28 & 33 \\
\hline 95 & 2006 & 2 & 2 & 22 & 44 & 17.5 & 36.5153 & 137.5195 & 7.4 & 1.5 & 253 & 57 & -122 & 20 & 19 & 49 \\
\hline 96 & 2006 & 2 & 4 & 7 & 10 & 39.8 & 36.4877 & 137.4412 & 8.2 & 1.7 & 247 & 80 & -152 & 24 & 26 & 47 \\
\hline 97 & 2006 & 2 & 4 & 7 & 20 & 47.2 & 36.4887 & 137.4410 & 8.4 & 1.2 & 226 & 63 & -154 & 34 & 27 & 23 \\
\hline 98 & 2006 & 2 & 4 & 22 & 25 & 51 & 36.6588 & 136.9482 & 16.5 & 1.3 & 233 & 44 & 87 & 27 & 33 & 31 \\
\hline 99 & 2006 & 2 & 5 & 2 & 25 & 19.4 & 36.4855 & 137.4408 & 7.9 & 1.7 & 90 & 85 & -146 & 17 & 22 & 65 \\
\hline 100 & 2006 & 2 & 9 & 23 & 50 & 1.5 & 36.6203 & 137.5967 & 25.6 & 1.3 & 45 & 57 & 136 & 28 & 46 & 26 \\
\hline 101 & 2006 & 2 & 15 & 14 & 49 & 48.1 & 36.2243 & 137.5057 & 2.5 & 1.8 & 255 & 67 & 150 & 32 & 35 & 50 \\
\hline 102 & 2006 & 2 & 19 & 2 & 40 & 8.5 & 36.4957 & 137.4613 & 8.9 & 1.1 & 72 & 69 & -179 & 37 & 32 & 30 \\
\hline 103 & 2006 & 2 & 19 & 10 & 34 & 50.9 & 36.2672 & 136.9822 & 7.7 & 1.3 & 267 & 63 & 169 & 21 & 27 & 43 \\
\hline 104 & 2006 & 3 & 9 & 3 & 56 & 9.3 & 36.4920 & 137.6122 & 33 & 1.2 & 262 & 19 & -97 & 10 & 10 & 59 \\
\hline 105 & 2006 & 4 & 20 & 0 & 13 & 34.1 & 36.3355 & 137.1473 & 9.3 & 1.2 & 77 & 86 & -163 & 28 & 28 & 33 \\
\hline 106 & 2006 & 4 & 26 & 14 & 10 & 54.8 & 36.5027 & 137.3045 & 10.6 & 1.3 & 248 & 87 & -166 & 30 & 32 & 24 \\
\hline 107 & 2006 & 4 & 29 & 1 & 13 & 17.2 & 36.3553 & 137.2120 & 8 & 1.5 & 26 & 85 & 164 & 26 & 27 & 62 \\
\hline 108 & 2006 & 5 & 1 & 22 & 38 & 14.8 & 36.3548 & 137.2050 & 6.4 & 0.9 & 296 & 43 & 112 & 31 & 42 & 26 \\
\hline 109 & 2006 & 5 & 3 & 21 & 16 & 4.8 & 36.3683 & 137.2290 & 8.2 & 2.2 & 237 & 79 & 123 & 16 & 15 & 73 \\
\hline 110 & 2006 & 5 & 9 & 0 & 37 & 11.1 & 36.4605 & 136.7918 & 9.1 & 1 & 149 & 46 & -139 & 27 & 29 & 25 \\
\hline 111 & 2006 & 5 & 10 & 6 & 46 & 24.3 & 36.3555 & 137.2065 & 6.5 & 1.3 & 165 & 15 & 9 & 20 & 29 & 27 \\
\hline 112 & 2006 & 5 & 11 & 19 & 28 & 1.5 & 36.2848 & 137.0517 & 8 & 1.3 & 38 & 89 & -157 & 23 & 20 & 42 \\
\hline 113 & 2006 & 5 & 24 & 21 & 18 & 23.2 & 36.5050 & 137.4788 & 9.3 & 1.6 & 64 & 82 & -150 & 34 & 38 & 50 \\
\hline 114 & 2006 & 5 & 29 & 12 & 10 & 16.2 & 36.6305 & 136.9917 & 17.5 & 1.3 & 223 & 74 & 125 & 33 & 31 & 32 \\
\hline 115 & 2006 & 6 & 5 & 7 & 5 & 52.4 & 36.6720 & 136.9623 & 22.8 & 1.1 & 1 & 86 & 65 & 35 & 46 & 13 \\
\hline 116 & 2006 & 6 & 11 & 12 & 32 & 30 & 36.6037 & 137.2748 & 14 & 1.6 & 68 & 49 & 131 & 17 & 8 & 48 \\
\hline 117 & 2006 & 6 & 12 & 21 & 24 & 13.3 & 36.3238 & 137.1455 & 9.2 & 1.4 & 90 & 87 & -170 & 20 & 27 & 58 \\
\hline 118 & 2006 & 6 & 16 & 17 & 30 & 55.3 & 36.5585 & 136.8428 & 12.1 & 1.7 & 79 & 44 & 122 & 27 & 26 & 57 \\
\hline 119 & 2006 & 6 & 17 & 6 & 26 & -0.4 & 36.5953 & 136.8592 & 6.5 & 1.4 & 52 & 73 & -161 & 23 & 24 & 41 \\
\hline 120 & 2006 & 6 & 24 & 2 & 25 & 26.1 & 36.3665 & 137.1522 & 5.6 & 2.6 & 354 & 71 & 130 & 19 & 20 & 72 \\
\hline 121 & 2006 & 6 & 28 & 12 & 40 & 42.6 & 36.2820 & 137.0348 & 5.9 & 0.9 & 81 & 61 & 144 & 36 & 34 & 18 \\
\hline 122 & 2006 & 7 & 8 & 3 & 37 & 21.6 & 36.4815 & 137.3762 & 8.7 & 1.1 & 249 & 63 & 164 & 25 & 25 & 26 \\
\hline 123 & 2006 & 7 & 9 & 19 & 5 & 25.1 & 36.2390 & 136.8993 & 5 & 0.3 & 267 & 88 & 140 & 44 & 39 & 9 \\
\hline 124 & 2006 & 7 & 13 & 19 & 50 & 16 & 36.3090 & 137.0507 & 9.6 & 1.1 & 264 & 87 & -178 & 30 & 36 & 18 \\
\hline 125 & 2006 & 7 & 20 & 16 & 17 & 25.6 & 36.2983 & 136.9977 & 4.5 & 1.2 & 228 & 56 & 133 & 36 & 33 & 20 \\
\hline 126 & 2006 & 7 & 23 & 22 & 12 & 1.5 & 36.3955 & 137.2542 & 5.5 & 1.7 & 304 & 77 & -172 & 29 & 27 & 37 \\
\hline 127 & 2006 & 7 & 27 & 6 & 51 & 44.9 & 36.3710 & 137.2192 & 6.8 & 0.8 & 243 & 70 & 129 & 39 & 34 & 12 \\
\hline 128 & 2006 & 7 & 31 & 6 & 29 & 32.8 & 36.2648 & 136.9708 & 8.1 & 0.1 & 89 & 50 & 180 & 33 & 33 & 13 \\
\hline 129 & 2006 & 8 & 2 & 20 & 29 & 4.6 & 36.3410 & 137.0505 & 5.8 & 0.7 & 212 & 75 & 133 & 38 & 33 & 16 \\
\hline 130 & 2006 & 8 & 7 & 5 & 55 & 13.6 & 36.2312 & 136.9085 & 6.8 & 1.5 & 246 & 76 & -170 & 28 & 26 & 28 \\
\hline 131 & 2006 & 8 & 7 & 6 & 6 & 1 & 36.2322 & 136.9085 & 7 & 0.7 & 46 & 73 & -177 & 34 & 35 & 17 \\
\hline 132 & 2006 & 8 & 7 & 6 & 13 & 32.4 & 36.2315 & 136.9077 & 6.6 & 1.2 & 249 & 65 & -170 & 37 & 30 & 27 \\
\hline 133 & 2006 & 8 & 18 & 13 & 30 & 46.8 & 36.4908 & 137.4337 & 9.9 & 1.6 & 35 & 69 & 123 & 35 & 43 & 23 \\
\hline 134 & 2006 & 8 & 28 & 2 & 30 & 9.5 & 36.3613 & 137.2290 & 9.4 & 1.7 & 46 & 82 & -170 & 20 & 19 & 56 \\
\hline 135 & 2006 & 8 & 31 & 19 & 41 & 39.1 & 36.3225 & 137.1528 & 11.1 & 1.4 & 92 & 81 & -174 & 20 & 21 & 42 \\
\hline 136 & 2006 & 8 & 31 & 19 & 43 & 35.8 & 36.3275 & 137.1453 & 10.6 & 1 & 277 & 87 & 168 & 22 & 23 & 28 \\
\hline 137 & 2006 & 9 & 11 & 7 & 8 & 13.6 & 36.2770 & 136.9837 & 4.7 & 1.9 & 215 & 86 & 168 & 33 & 34 & 44 \\
\hline 138 & 2006 & 9 & 13 & 8 & 51 & 22.2 & 36.3838 & 137.1235 & 10.6 & 1.6 & 240 & 59 & -132 & 19 & 16 & 33 \\
\hline 139 & 2006 & 9 & 15 & 7 & 14 & 29.7 & 36.3710 & 137.2305 & 6.8 & 2.1 & 250 & 60 & -144 & 22 & 16 & 47 \\
\hline 140 & 2006 & 9 & 15 & 23 & 47 & 20.6 & 36.5580 & 137.0482 & 10.1 & 1.2 & 46 & 40 & 121 & 25 & 20 & 29 \\
\hline 141 & 2006 & 9 & 17 & 7 & 6 & 24.4 & 36.3498 & 137.1915 & 8.4 & 1.9 & 62 & 88 & -176 & 23 & 24 & 55 \\
\hline 142 & 2006 & 9 & 20 & 9 & 13 & 18.9 & 36.3572 & 136.9750 & 4.1 & 1.4 & 228 & 85 & -174 & 32 & 37 & 30 \\
\hline 143 & 2006 & 10 & 30 & 12 & 23 & 23.2 & 36.3657 & 137.2180 & 5.2 & 1.3 & 224 & 63 & 112 & 40 & 39 & 27 \\
\hline 144 & 2006 & 11 & 3 & 19 & 26 & 1.4 & 36.3415 & 136.8425 & 7.9 & 1.1 & 217 & 74 & -156 & 27 & 29 & 19 \\
\hline 145 & 2006 & 11 & 5 & 4 & 58 & 14.1 & 36.5102 & 136.7505 & 12.3 & 1.5 & 15 & 24 & 69 & 28 & 26 & 38 \\
\hline 146 & 2006 & 11 & 11 & 21 & 51 & 8.8 & 36.2873 & 137.0525 & 6.1 & 1.3 & 252 & 84 & -170 & 33 & 34 & 25 \\
\hline 147 & 2006 & 11 & 17 & 0 & 58 & 21.5 & 36.5355 & 137.6720 & 3 & 1.3 & 29 & 75 & 169 & 38 & 32 & 23 \\
\hline 148 & 2006 & 11 & 18 & 1 & 36 & 48.5 & 36.5437 & 137.6768 & 2.6 & 1.1 & 224 & 64 & -171 & 37 & 29 & 19 \\
\hline 149 & 2006 & 12 & 1 & 1 & 35 & 57.2 & 36.2478 & 136.8432 & 5.1 & 1.3 & 245 & 61 & 125 & 28 & 28 & 21 \\
\hline 150 & 2006 & 12 & 17 & 6 & 16 & 13.1 & 36.3517 & 137.1930 & 10 & 1.4 & 190 & 21 & 133 & 13 & 15 & 33 \\
\hline 151 & 2006 & 12 & 29 & 1 & 26 & 5.9 & 36.3967 & 136.8188 & 9.8 & 2.3 & 60 & 54 & 136 & 31 & 36 & 25 \\
\hline
\end{tabular}

E1, E2: the fault plane uncertainty and the auxiliary plane uncertainty NP: the number of $\mathrm{P}$-wave polarity data

Q: Quality of solutions

the depth of hypocenters was almost the same $(\sim 11 \mathrm{~km})$.

\subsection{Stress tensor inversion}

For the stress tensor inversion, the study area was gridded with $15^{\prime}(23 \mathrm{~km})$ and $10^{\prime}(18 \mathrm{~km})$ spacing in E-W and N-S directions, respectively (Fig. 11). The inversion was carried out at each node in the center of $10^{\prime} \times 15^{\prime}$ rectangle using all events within the rectangle. The nine nodes in Fig. 11 labeled as $(0,0),(1,0),(2,0),(0,1),(1,1),(2,1),(0,2)$, $(1,2)$, and $(2,2)$ include $27,3,1,14,62,9,13,2$, and 4 focal mechanism solutions, respectively. The 5 nodes with more than 8 events were included in the inversion. The nodes with less than 8 events were used just to smooth gaps in the seismicity and the results were not adopted. We chose the damping parameter $e$ (equation (14) in Hardebeck and Michael (2006)) on the basis of the trade-off curve between model length and data variance (Fig. 11). The corner of the trade-off curve was around $e \approx 1$, so we chose $e=1$.

We obtained the stress parameters at 5 nodes (Fig. 11, Table 2). The orientation of the maximum principal stress $\left(\sigma_{1}\right)$ is very similar to each other at all nodes: $(0,0),(0,1)$, $(0,2),(1,1)$, and $(2,1)$. The $\sigma_{1}$ trends from $\mathrm{N} 72^{\circ} \mathrm{W}$ to $\mathrm{N} 77^{\circ} \mathrm{W}$ and dips nearly horizontally, which is consistent 


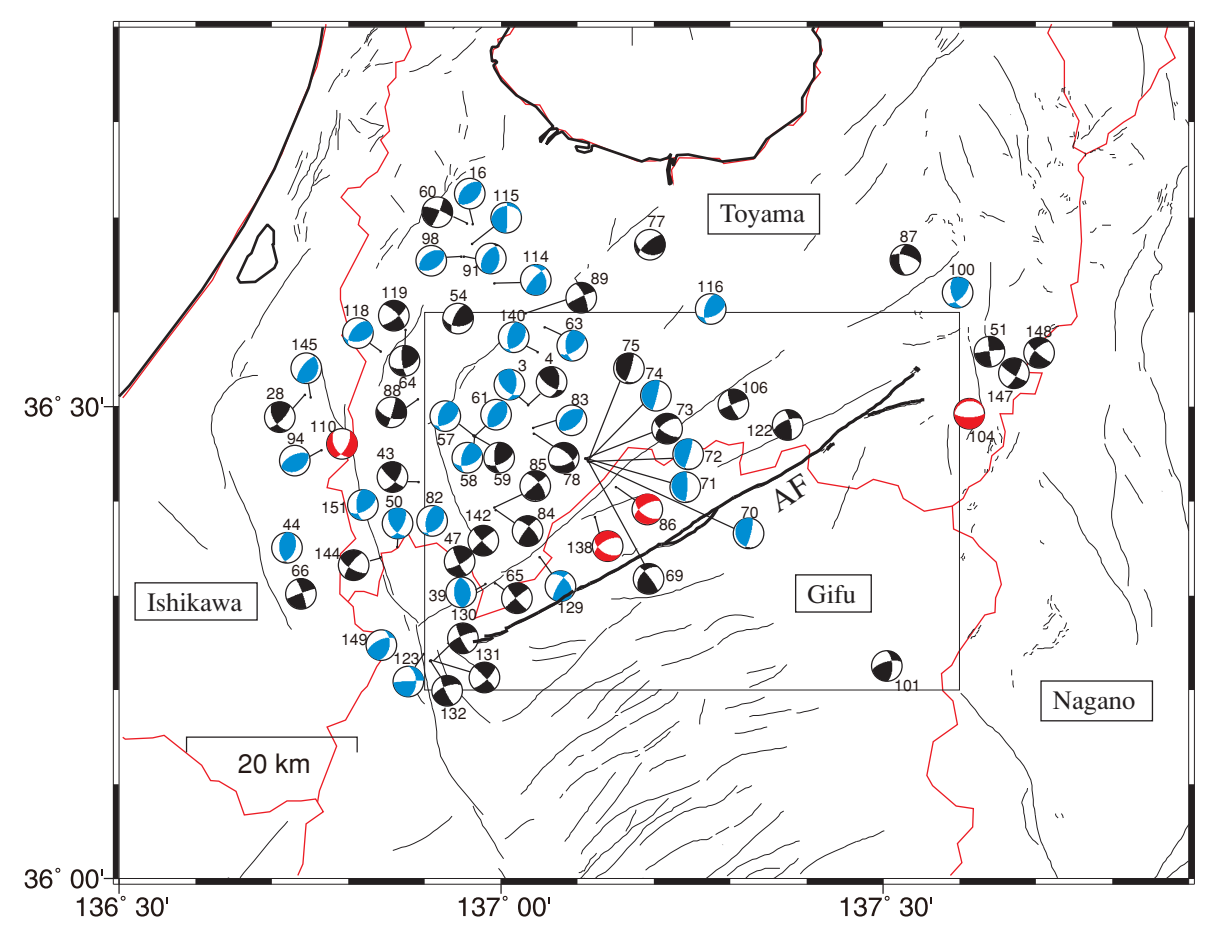

Fig. 5. Spatial distribution of focal mechanism solutions obtained in this study. Mechanisms with Quality A to D were plotted. All diagrams are equal area projection on the lower hemisphere of focal sphere. Colored areas show compressional quadrants. Note that the solutions with epicenters located within $5 \mathrm{~km}$ from the surface trace of the Atotsugawa fault are not plotted. The rectangle indicates the area shown in Fig. 6(a). Numbers labeled on each solution correspond to the event number of Table 1 . Solutions in red indicate normal-fault type events with rakes from $-140^{\circ}$ to $-40^{\circ}$. Solutions in blue indicate reverse-fault type events with rakes from $+40^{\circ}$ to $+140^{\circ}$. Solutions in black show events with remaining range of rake. A bold line labeled as AF is the surface trace of Atotsugawa fault. Thin lines are the other active faults. The name of prefectures is indicated in rectangles, and red lines show their boundaries.

with the average trend and dip of $P$-axis. The azimuth of $\sigma_{1}$ is well-constrained and reliable at the nodes $(0,1)$, $(1,1)$, and $(2,1)$ with the 1 -sigma uncertainty of $19^{\circ}, 22^{\circ}$, and $21^{\circ}$, respectively. However the uncertainty of the dip angle is rather large. Except for the node $(0,2)$ the azimuth of the minimum principal stress $\left(\sigma_{3}\right)$ ranges from $\mathrm{N} 14^{\circ} \mathrm{E}$ to $\mathrm{N} 20^{\circ} \mathrm{E}$, which is also consistent with the average direction of $T$-axis. Since the uncertainty of the azimuth is small at the nodes $(0,0),(1,1)$, and $(2,1)$, the inversion results are reliable. Although the azimuth at the node $(0,2)$ is different from the neighboring grids, it is not significant because the uncertainty is very large. The intermediate principal stress $\left(\sigma_{2}\right)$ has a near vertical dip except for the node $(0,2)$. Even if the uncertainty takes into account, the dip angle is larger than $45^{\circ}$, indicating a near vertical dip rather than a near horizontal dip.

When making a discussion on the relative magnitude of three principal stresses, the stress ratio $R$ defined as $R=\left(\sigma_{1}-\sigma_{2}\right) /\left(\sigma_{1}-\sigma_{3}\right)$ provides a valuable information. The stress ratios $R$ are 0.77 and 0.96 at the node $(0,0)$ and $(0,1)$ around the southwestern end of the Atotsugawa fault. These stress ratios are close to unity, indicating $\sigma_{2} \approx \sigma_{3}$. It is natural to assume that vertical stress is close to the lithostatic stress or the overburden pressure. Thus we interpret that both $\sigma_{2}$ and $\sigma_{3}$ are equal to the lithostatic stress in the area around the southwestern edge of the Atotsugawa fault. On the other hand, the stress ratio $R$ is approximately 0.5 at the nodes $(1,1)$ and $(2,1)$ around the central part and the northeastern edge of the Atotsugawa fault. In these subareas we modeled that the compressional tectonic stress is equal to the extensional tectonic stress. If the magnitude of the compressional tectonic stress changes little spatially in the Atotsugawa fault area, which is suggested by fairly uniform maximum horizontal compressive stress $\left(S_{H \max }\right)$ directions not only in the Atotsugawa fault area but also in regional scale (Townend and Zoback, 2006), the stress ratio implies relatively larger extensional tectonic stress in the central part of the fault than in the southwestern edge. Though the uncertainty of the stress ratio $R$ is large, it is interesting that the spatial change in relative stress magnitudes is modeled.

\section{Discussion}

\subsection{Comparison with previous studies on focal mecha- nisms}

Stress field in the northern Hida region including the Atotsugawa fault zone has been investigated by Mikumo et al. (1985, 1988), Koizumi et al. (1993), and Wada et al. (2003) on the basis of focal mechanism data. Mikumo et al. $(1985,1988)$ showed that focal mechanisms along and westward extension of Atotsugawa fault are mostly strikeslip with ENE-WSW trending nodal planes. Outside the Atotsugawa fault zone, they found reverse faulting events in the northwestern part and normal faulting events in the northern part. Koizumi et al. (1993) showed that the major faulting type is strike-slip with $\mathrm{N} 60-80^{\circ} \mathrm{W}$ trend of $P$ axis. They found that reverse faulting earthquakes are predominant in the southern part of Hida mountains and in the northern part of Miboro fault, and normal faulting events are located in the Hida region and southern end of Toyama 

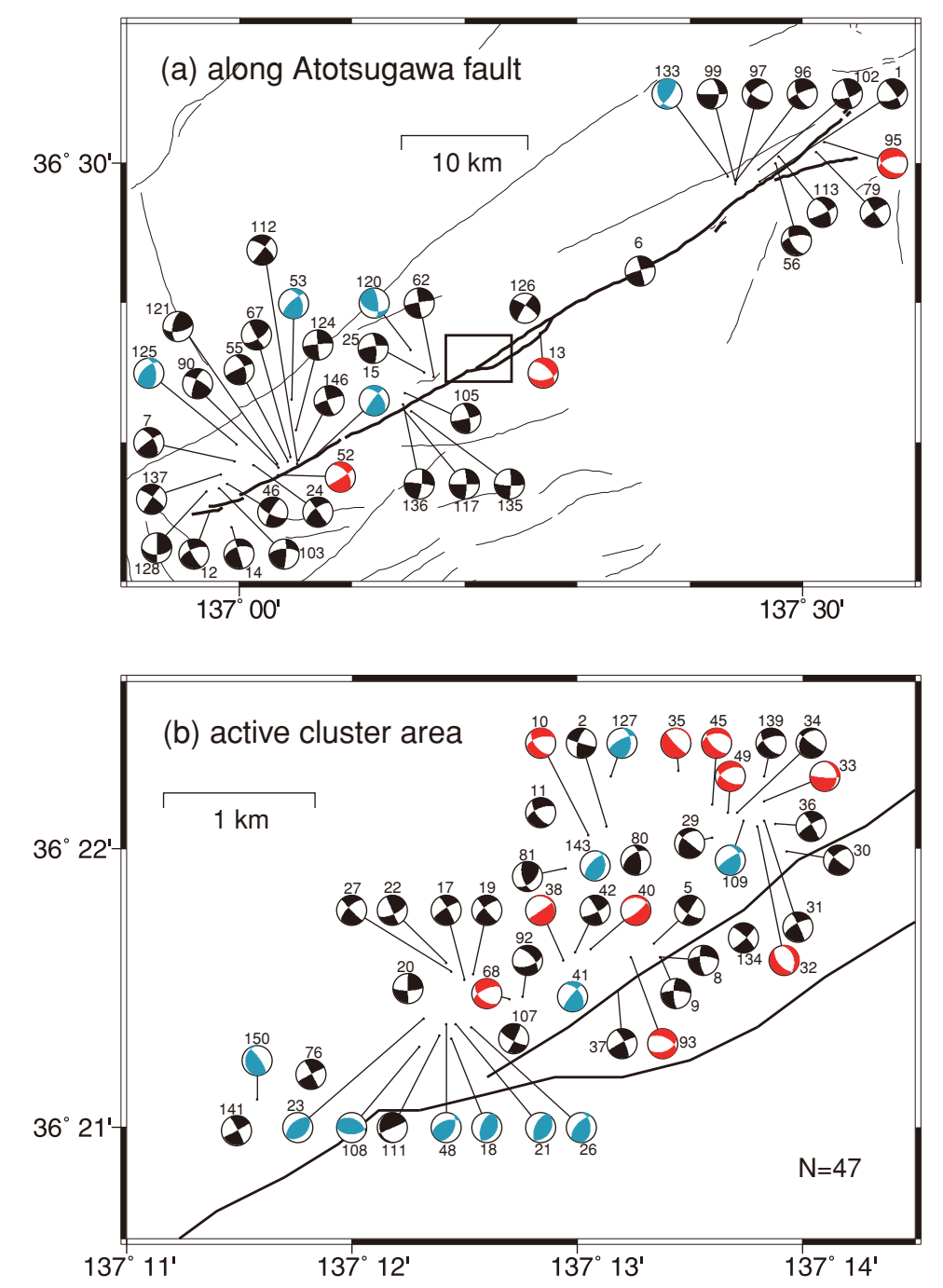

Fig. 6. As in Fig. 5 but for events located within $5 \mathrm{~km}$ from the surface trace of Atotsugawa fault. Solutions are not plotted in the rectangle in (a) that indicates the area shown in (b). Solutions in red, blue, and black indicate normal-fault type events, reverse-fault type events, and other types, respectively.

Plane. In these studies the magnitude threshold of earthquakes whose focal mechanisms could be determined was about 3.0. Wada et al. (2003) determined focal mechanisms of small to micro earthquakes with magnitudes down to 1.5 using data obtained after the deployment of dense nationwide seismographic network of Hi-net. They also showed that both strike-slip and reverse faulting are the common focal mechanisms in the northern Hida region, however, they pointed out the spatial variation along the Atotsugawa fault. Our newly determined focal mechanisms (Figs. 5 and 6) confirm that strike-slip events are predominant along the Atotsugawa fault and reverse faulting events are also distributed in the area to the northwest of fault.

Recently Watanabe (2008) argued the cause of spatial variation of dominant focal mechanisms from the strikeslip in the Hida area to the reverse fault in the Toyama area. He attributed the change into reduced vertical stress in the Toyama Plain due to thick sedimentary layer with lower density. However, our focal mechanisms show no clear correlation with the topography (Fig. 5). Watanabe's (2008) interpretation is based on the idea of isostasy of the crust, which seems skeptical for us if the isostatic balance holds even in a small area like the Toyama Plain.

In the area along the Atotsugawa fault, Wada et al. (2003) indicated the dominance of reverse faulting events in the southwestern edge of fault and a coexistence of variety of faulting types in the northeastern edge. They infer the effect of Ushikubi and Mozumi-Sukenobu faults adjoining to the Atotsugawa fault to produce these non-strike-slip mechanisms. Contrary to their results, our focal mechanism data show the dominance of strike-slip events in the clusters both in the southwestern and northeastern edge of Atotsugawa fault (Fig. 6). There are several possible reasons to account for the difference. The one is due to the difference in the earthquake magnitudes. Our data span a magnitude range from -0.1 to 4.4 , mostly less than 1.5 , which is systematically lower than the range examined by Wada et al. (2003). Generally focal mechanisms of smaller events are less reliable due to insufficient number of $P$-wave first motion data. If there are few data points near the center of focal sphere, that means lack of stations near the epicenter, the focal mechanism can be interpreted as either strikeslip or dip slip. However, our data was obtained by the dense temporary observation and the quality of solutions 


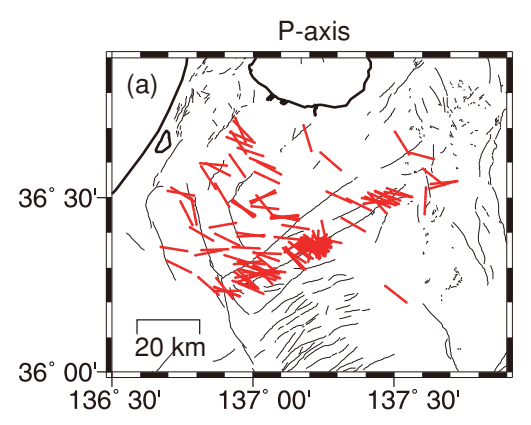

(b) Dip of P-axis

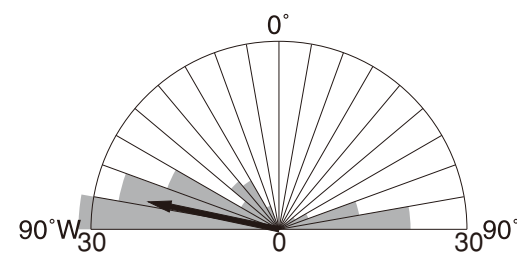

(c) Strike of P-axis NORTH

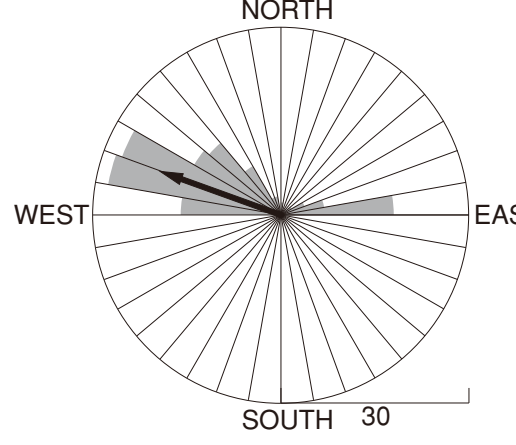

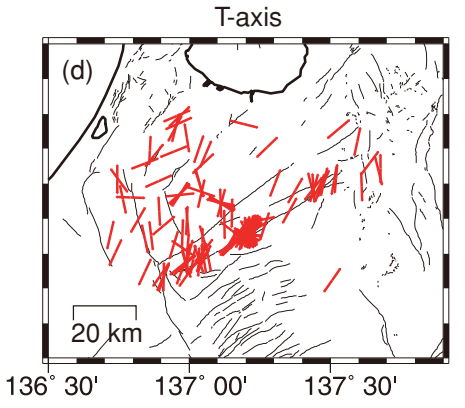

(e) Dip of T-axis

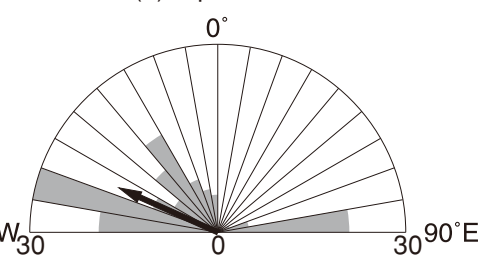

(f) Strike of T-axis NORTH

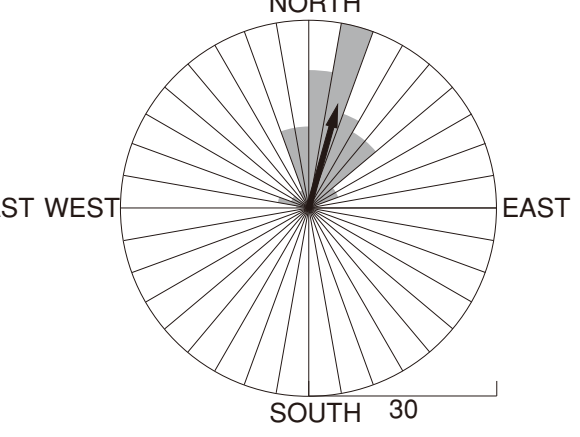

Fig. 7. Orientation of $P$ - and $T$-axes of focal mechanism solutions shown in Fig. 5. Red lines in (a) and (d) indicate the strike of $P$ - and $T$-axes, respectively. Black lines display active faults. Dip angles are shown in (b) and (e) for $P$ - and $T$-axes, respectively. $90^{\circ}$ indicates a horizontal axis. Arrows show the average dip angle: $78^{\circ}$ for $P$-axis and $66^{\circ}$ for $T$-axis. Azimuths are shown in (c) and (f) for $P$ - and $T$-axes, respectively. Arrows show the average azimuth: $\mathrm{N} 70^{\circ} \mathrm{W}$ for $P$-axis and $\mathrm{N} 16^{\circ} \mathrm{E}$ for $T$-axis.

was controlled by the HASH technique. The adopted focal mechanisms (Table 1) have qualities classified as A to D. Unfortunately we cannot derive a definite conclusion if the event size is the cause of difference between our result and that by Wada et al. (2003) because we cannot evaluate the quality of their solutions. The other possibility is the temporal change in seismic activity. Our data spans two years from January 2005 to December 2006 whereas the data by Wada et al. (2003) were obtained in a former period from October 2001 to January 2003. General feature of seismicity shown in Fig. 3 is common to the seismicity map by Wada et al. (2003) except high seismicity in our data at the central cluster along the Atotsugawa fault. Since the seismicity in Fig. 3 is quite similar to that by Mikumo et al. (1988) in a period from 1980 to 1986 , it is clear that there was a temporal change in seismicity in the central part of fault. This change might be associated with the variation of the dominant type of focal mechanisms at both edges of fault.

One interesting feature of stress field in the study area is the fixed direction of $\sigma_{1}$ axis while the type of faulting is variable as shown in Figs. 5 and 6 . The $\sigma_{1}$ axes shown in Fig. $11\left(\mathrm{~N} 72^{\circ}-77^{\circ} \mathrm{W}\right)$ are quite similar to the maximum horizontal compressive stress $\left(S_{H \max }\right)$ directions estimated by Townend and Zoback (2006) for regional scale including our study area. Tsukahara and Kobayashi (1991) showed that $S_{H \max }$ direction in central to southwestern Japan is fairly uniform trending WNW-ESE and there is no obvious correlation with topography and surface geology. Although the direction is approximately the same as that of movement of Pacific plate, the stress field is not attributed to the plate motion. They suggested a large scale crustal movement of Japan Sea or Eastern Asia to produce the stress field. Ito (1990) presented similar interpretation.

\subsection{Angles between stress direction and fault strike}

In 4.3 we estimated the azimuth of $\sigma_{1}$ by applying the stress tensor inversion technique to the presently obtained focal mechanism data. The direction of the surface trace of Atotsugawa fault is approximately $\mathrm{N} 60^{\circ} \mathrm{E}$. Therefore the direction of $\sigma_{1}$ and the fault trace form an angle of $43^{\circ}-48^{\circ}$. Even if the estimation error is taking into account, it is clear that the $\sigma_{1}$ axis is neither perpendicular nor parallel to the Atotsugawa fault. There are two competing models for the frictional strength of the San Andreas Fault in California (Hardebeck and Michael, 2004): the strong-fault model and the weak-fault model. The strong fault model (Scholz, 2000) predicts the maximum horizontal compressive stress axis forms low angles to the fault, while the relatively weak 


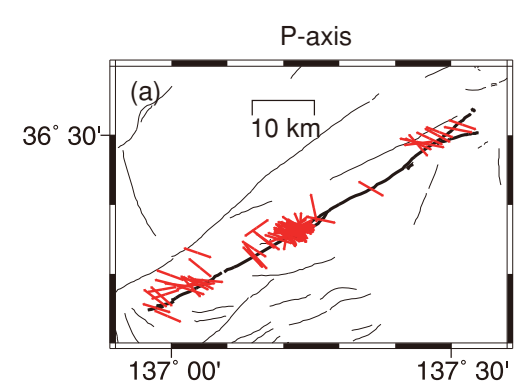

(b) Dip of P-axis

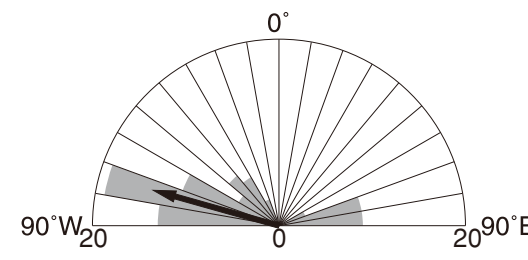

(c) Strike of P-axis NORTH

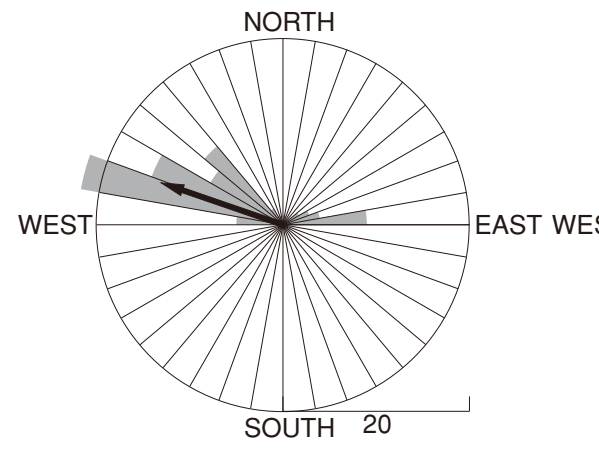

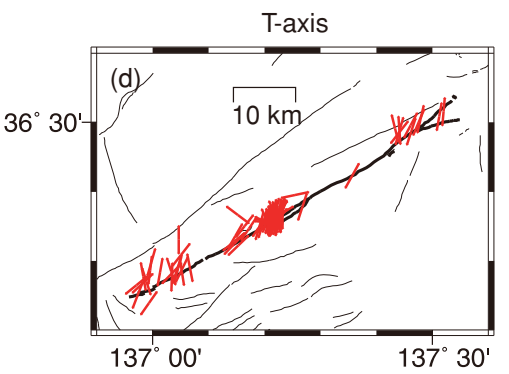

(e) Dip of T-axis

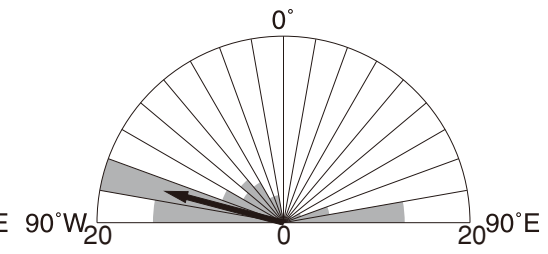

(f) Strike of T-axis NORTH

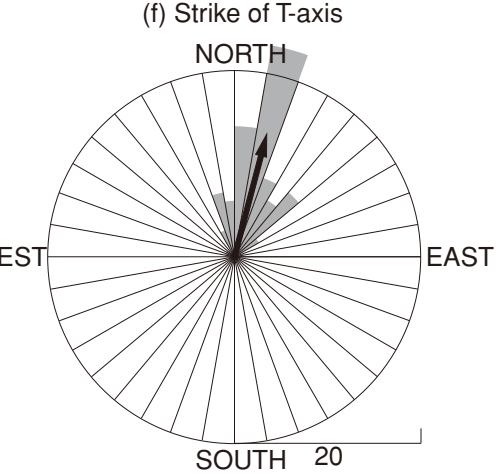

Fig. 8. Orientation of $P$ - and $T$-axes of focal mechanism solutions shown in Fig. 6(a). Red lines in (a) and (d) indicate the strike of $P$ - and $T$-axes, respectively. A bold black line and thin lines express the Atotsugawa fault and other active faults. Dip angles are shown in (b) and (e) for $P$ - and $T$-axes, respectively. $90^{\circ}$ indicates a horizontal axis. Arrows show the average dip angle: $74^{\circ}$ for $P$-axis and $75^{\circ}$ for $T$-axis. Azimuths are shown in (c) and (f) for $P$ - and $T$-axes, respectively. Arrows show the average azimuth: N71 ${ }^{\circ} \mathrm{W}$ for $P$-axis and $\mathrm{N} 15^{\circ} \mathrm{E}$ for $T$-axis.

fault model (Zoback, 2000; Townend and Zoback, 2001) predicts high angles. Hardebeck and Michael (2004) proposed an extreme model in which all major active faults are weak. Yamamoto et al. (2002) made stress measurements using borehole cores sampled at sites close to the Nojima fault that ruptured during the 1995 Hyogo-ken Nanbu earthquake $\left(M_{\mathrm{JMA}}=7.3\right)$. Since the direction of the largest horizontal stress is almost perpendicular to the strike of fault, they interpreted Nojima fault as weak fault. Our observation in the Atotsugawa fault shows high angles $\left(\sim 45^{\circ}\right)$, which suggests strong frictional strength of Atotsugawa fault.

Recently Mizuno et al. (2005) estimated the $S_{H \max }$ direction from the shear-wave splitting analysis for small earthquakes around the Atotsugawa fault. They found that the angle $\phi$ between the $S_{H \max }$ direction and fault strike decreases from $55-80^{\circ}$ at the stations $2-8 \mathrm{~km}$ from the fault to $45^{\circ}$ at the stations within $1 \mathrm{~km}$ from the fault. They interpreted the result as the local stress accumulation due to the localized flow or slip along the deep extension of fault. Our stress tensor inversion is not suitable to discuss such tendency because the stress tensors are estimated for blocks around the fault (Fig. 11). Figures 8 and 9, however, show no systematic variation of angle between the $P$-axis and the fault trace with the distance from the fault. Rather, there is considerable variation of angles along the fault. The $S_{H \max }$ direction by Mizuno et al. (2005) is deduced from the idea of stress-aligned crack-induced shear-wave splitting that is widely observed in the Earth's crust (e.g., Crampin, 1994). We should note that alignment of grains and intergranular pores not related to present-day stress can give rise to high anisotropy determined by the tectonic history of the rock (Crampin and Peacock, 2005). The anisotropy analysis has additional uncertainty to specify the location of anisotropic body because the observed anisotropy is the contribution through the whole ray path. Thus we think our focal mechanisms are more direct indicator of present-day stress state around the fault.

\subsection{Normal-faulting earthquakes}

Mikumo et al. (1985) pointed out local stress perturbation in an area bounded by Toyama Plain, Miboro fault, and Ushikubi fault. They found several earthquakes with normal faulting in an area of southwestward continuation of the Toyama Plain. Koizumi et al. (1993) showed normal faulting events are located in the Hida region and southern end of Toyama Plane. Though Wada et al. (2003) did not mention normal faulting events, we see some events along the Atotsugawa fault in their figure. In our focal mechanism data, three normal faulting events are located around the fault (Fig. 5) and many events are distributed in the active 


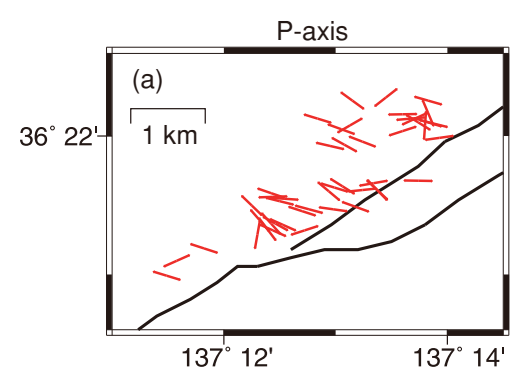

(b) Dip of P-axis

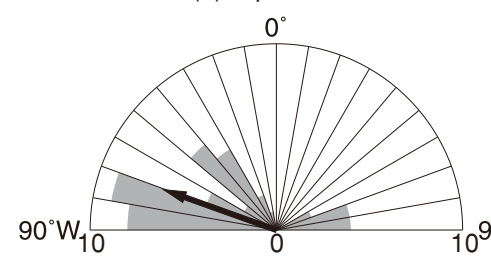

(c) Strike of P-axis NORTH

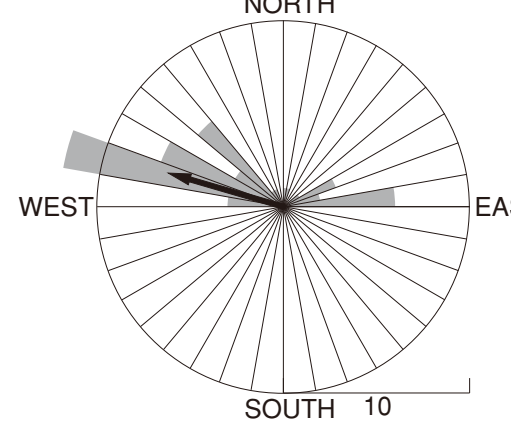

T-axis

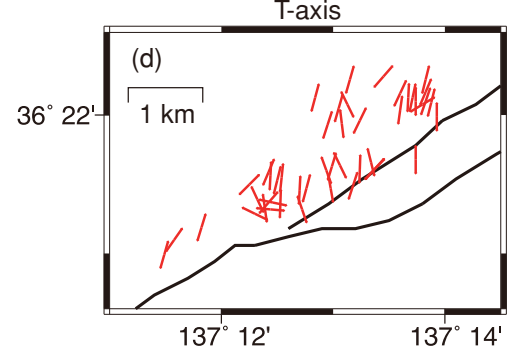

(e) Dip of T-axis

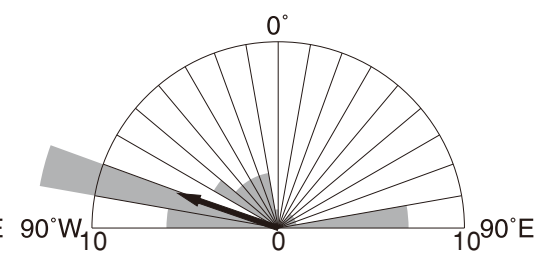

(f) Strike of T-axis NORTH

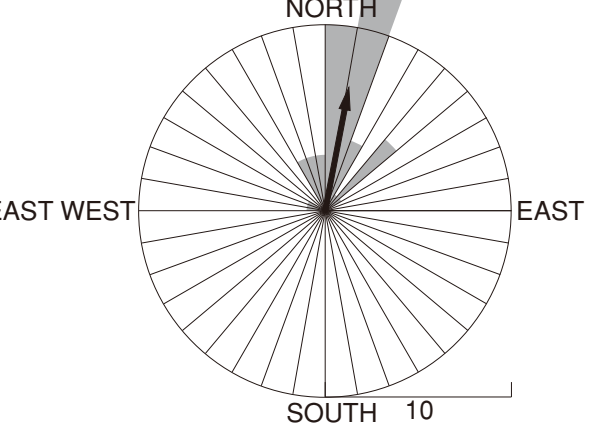

Fig. 9. As in Fig. 8 but for solutions shown in Fig. 6(b). Red lines in (a) and (d) indicate the strike of $P$-and $T$-axes, respectively. A bold black line is the Atotsugawa fault. Arrows show the average dip angle in (b) and (e): $70^{\circ}$ for $P$-axis and $71^{\circ}$ for $T$-axis, and the average azimuth in (c) and (f): $\mathrm{N} 74^{\circ} \mathrm{W}$ for $\mathrm{P}$-axis and $\mathrm{N} 11^{\circ} \mathrm{E}$ for $\mathrm{T}$-axis.

Table 2. Orientation of principal stresses and stress ratio in the study area. The location of grid is shown in Fig. 11(b). Azimuth is measured clockwise from the north in degrees. Dip is measured downward from the horizontal surface in degrees. Stress ratio is defined by $R=\left(\sigma_{1}-\sigma_{2}\right) /\left(\sigma_{1}-\sigma_{3}\right)$. The values in the brackets indicate the range of uncertainty.

\begin{tabular}{|c|c|c|c|c|c|c|c|c|c|c|c|c|c|c|}
\hline \multirow{2}{*}{ Grid } & \multicolumn{4}{|c|}{ Maximum principal stress $\sigma_{1}$} & \multicolumn{4}{|c|}{ Intermediate principal stress $\sigma_{2}$} & \multicolumn{4}{|c|}{ Minimum principal stress $\sigma_{3}$} & \multirow{2}{*}{\multicolumn{2}{|c|}{$R$}} \\
\hline & & Azimuth & & Dip & & Azimuth & & Dip & & Azimuth & & Dip & & \\
\hline$(0,0)$ & 75 & {$[-83,+$} & 2 & -18, & 21 & 157 & 71 & {$[+45$} & & {$[-172$,} & 19 & {$[-37$,} & 77 & \\
\hline$(0,1)$ & 77 & {$[-82,-63]$} & 2 & {$[-24,+10]$} & 170 & {$[-530$,} & 55 & {$[-25,+90]$} & 14 & {$[-165,+194]$} & 25 & {$[-65,+89]$} & 96 & ..0] \\
\hline$(0,2)$ & 75 & $-91,-54]$ & 12 & {$[-21,+19]$} & -169 & {$[-319,-127]$} & 19 & {$[-64,+84]$} & 45 & {$[-90,-205]$} & 68 & {$[-19,+90]$} & 0.72 & {$[0.4,1.0]$} \\
\hline$(1,1)$ & 103 & {$[+93,+115]$} & 12 & $2,+3$ & -24 & {$[-95,+$} & 70 & {$[+54,+88]$} & 54 & $4,-$ & 15 & {$[-5,+44]$} & 0.49 & 0.8] \\
\hline$(2,1)$ & 108 & {$[+99,+120]$} & 14 & {$[-19,+43]$} & -48 & {$[-227,+131]$} & 75 & {$[+46,+90]$} & -160 & {$[-172,-150]$} & 6 & {$[-15,+44]$} & 0.43 & {$[0.0,0.7]$} \\
\hline
\end{tabular}

Table 3. Orientation of principal stresses and stress ratio in the active cluster area. Azimuth is measured clockwise from the north in degrees. Dip is measured downward from the horizontal surface in degrees. Stress ratio is defined by $R=\left(\sigma_{1}-\sigma_{2}\right) /\left(\sigma_{1}-\sigma_{3}\right)$. The values in the brackets indicate the range of uncertainty.

\begin{tabular}{|c|c|c|c|c|c|c|c|c|c|c|c|c|c|c|}
\hline \multirow{2}{*}{$\begin{array}{c}\text { Depth } \\
{[\mathrm{km}]}\end{array}$} & \multicolumn{4}{|c|}{ Maximum principal stress $\sigma_{1}$} & \multicolumn{4}{|c|}{ Intermediate principal stress $\sigma_{2}$} & \multicolumn{4}{|c|}{ Minimum principal stress $\sigma_{3}$} & \multirow{2}{*}{\multicolumn{2}{|c|}{$R$}} \\
\hline & & Azimuth & & Dip & & zimuth & & Dip & & Azimuth & & Dip & & \\
\hline $0-8$ & 108 & {$[+93,+124]$} & 4 & {$[-15,+25]$} & -137 & {$[-316,+43]$} & 80 & {$[-9,+90]$} & 17 & {$[-141,+60]$} & 9 & {$[-77,+89]$} & 0.78 & {$[0.4,1.0]$} \\
\hline $8-20$ & 107 & {$[-23,+164]$} & 10 & {$[-73,+82]$} & -15 & {$[-77,-15]$} & 72 & {$[-10,+84]$} & -160 & {$[-172,-152]$} & 15 & {$[+3,+26]$} & 0.05 & {$[0.0,0.4]$} \\
\hline
\end{tabular}

cluster area (Fig. 6). In 4.3 we interpreted that extensional stress is relatively larger in the central part of fault than in the southwestern edge. The characteristic of normal faulting earthquakes is their similar focal depths around $11 \mathrm{~km}$. In order to investigate a change in stress field with depth, we applied the stress tensor inversion by SATSI again by dividing the grid $(1,1)$ that contains the active cluster area into two subgrids shallower and deeper than $8 \mathrm{~km}$. Both the shallow and deep portions include 25 focal mechanisms. Since the corner of the trade-off curve was around $e \approx 1$, the damping parameter was assumed again as $e=1$. The results are shown in Table 3. The inverted orientations of 

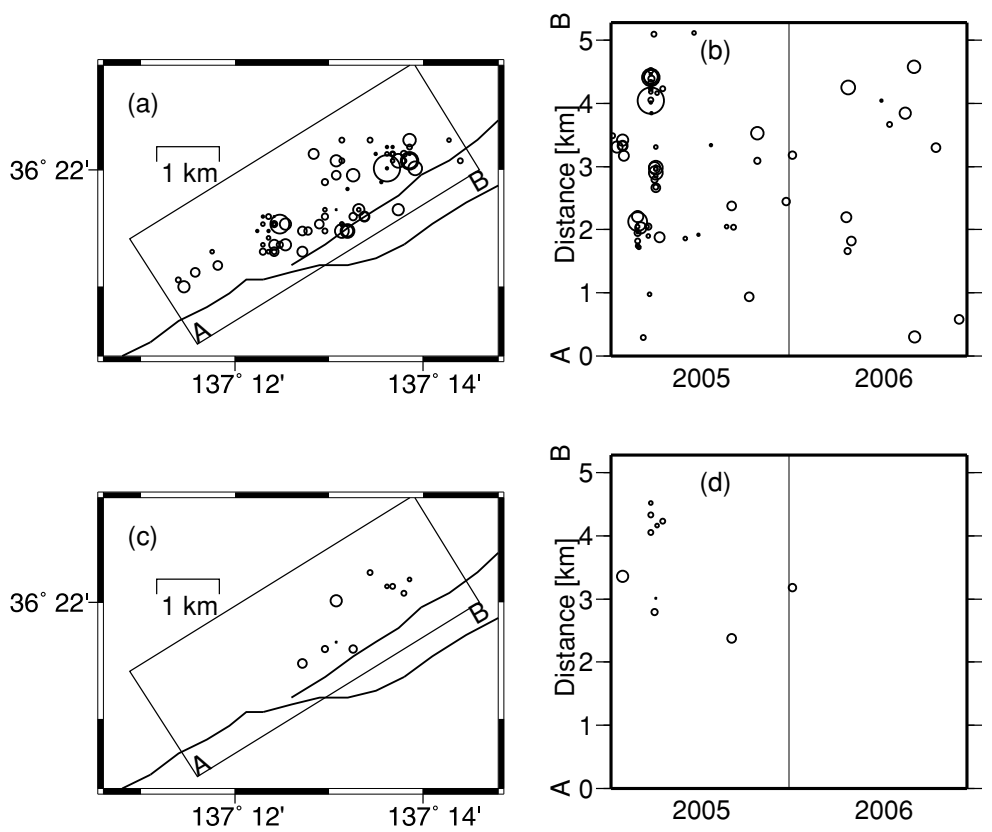

Fig. 10. Space-time distribution of earthquakes in the active cluster area. (a) All epicenters located in the period from January 2005 to December 2006. (b) Space-time distribution of the epicenters in the rectangle in (a). (c) and (d) show epicenters and space-time distribution for normal-fault-type events only.

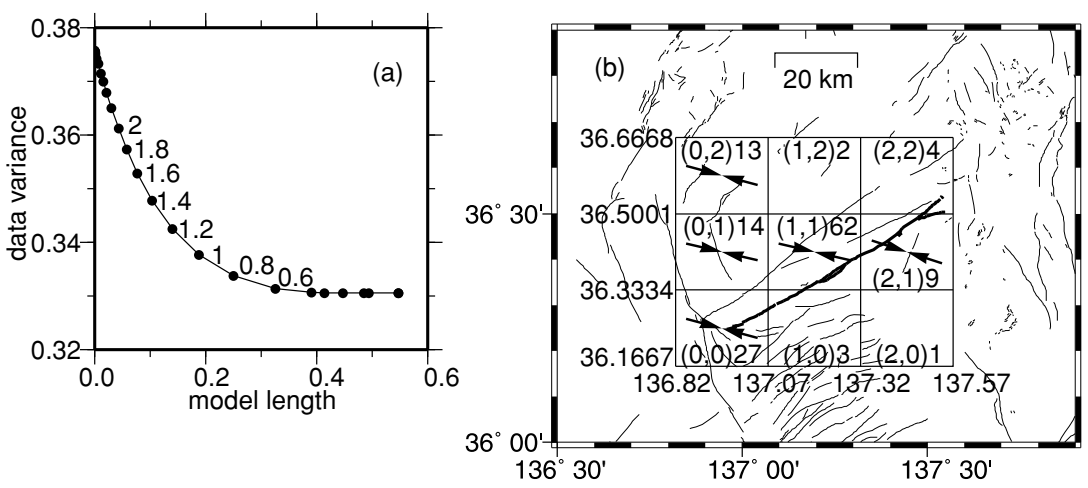

Fig. 11. (a) Trade-off curve of stress tensor inversion showing the model length and data variance for the full range of possible value of the damping parameter $e$. Numbers indicate values of $e$ at points marked by dots. (b) Inverted maximum principal stress $\left(\sigma_{1}\right)$ in the Atotsugawa fault area. Arrows indicate the azimuth of $\sigma_{1}$ at grid points centered at rectangles. Numbers within each rectangle indicate the coordinates of the grid point and the number of the focal mechanism solutions used for the stress tensor inversion. Bold and thin lines express the Atotsugawa fault and the other active faults, respectively.

$\sigma_{1}$ and $\sigma_{3}$ are almost the same as the results for the grid $(1,1)$ in Table 2 . There is no change in orientation between the shallow and the deep portions. On the other hand the stress ratio changes drastically with depth. The stress ratio is close to unity $(0.78)$ in the shallow portion, indicating that the compressional tectonic stress is predominant. Interestingly the stress ratio is nearly zero $(0.05)$ in the deep portion, suggestting the dominance of extensional tectonic stress.

\subsection{Comparison with tomographic studies}

The purpose of joint observation by the Japanese University Group was to investigate the relation between strain accumulation in the NKTZ and the occurrence of large earthquakes in the Zone. Here we compare the focal mechanisms and resultant stress tensors with the tomographic images obtained for the same purpose. Nakajima and Hasegawa (2007) estimated 3-D seismic velocity struc- ture in a broad area containing Atotsugawa fault. A distinct low-velocity zone particularly for the $P$-wave exists in the lower crust along the NKTZ, mainly at the southwest of the Itoigawa-Shizuoka Tectonic Line (ISTL). The width of the zone is comparable to that of NKTZ. Strike-slip events in Fig. 5 tend to exist over the low velocity zone in the lower crust found by Nakajima and Hasegawa (2007), while reverse faulting events are located in an area outside the zone. There is no systematic correlation of $P$ - and $T$-axes in Fig. 7 with the velocity structure. This means the structure in the lower crust does not affect the stress direction but influence the faulting type. As shown in 4.3, the $\sigma_{1}$ axis is horizontal and trend WNW-ESE throughout the study area. Strike-slip events are dominated in an area where $\sigma_{3}$ is horizontal and reverse faulting is the predominant type in an area where $\sigma_{2}$ is horizontal. It is generally considered that the vertical stress is close to the overburden pressure and 
changes little with position for a fixed depth. Therefore the area where strike-slip events are predominant is indicative of smaller horizontal stress in NNE-SSW direction than vertical stress. Nakajima and Hasegawa (2007) interpreted the low velocity zone reflects the existence of aqueous fluids or melts, which may have reduced the strength of both the crust and uppermost mantle, and consequently have promoted an anelastic deformation contributing to the contraction along the NKTZ. Strike-slip earthquakes preferentially distributed on the low-velocity zone suggest the effect of aqueous fluids or melts to reduce the horizontal stress as well in NNE-SSW direction.

Finer velocity structure along the Atotsugawa fault zone was imaged by Kato et al. (2006, 2007). They estimated 3 -D velocity structure by using natural earthquakes that occurred along and around the fault zone and artificial sources along and subperpendicular to the fault. They imaged high $V_{P}$ and high $V_{S}$ bodies in the western and eastern sections of the fault with depths greater than $2 \mathrm{~km}$, and a low $V_{P}$ zone in the central section with depths greater than $3 \mathrm{~km}$. The central section is also characterized by low $V_{P} / V_{S}(\sim 1.65)$ while the rest have moderate $V_{P} / V_{S}$ values. They interpreted that the high-velocity bodies in the western and eastern sections correspond to the Hida metamorphic rocks, and the body in the western section acted as the asperity of the 1858 Hietsu Earthquake $(M=7.0)$. They explained the low $V_{P} / V_{S}$ and the low $V_{P}$ in the central section by the presence of water-filled pores with high aspect ratios $(\sim 0.1)$. Generally the existence of fluids reduces the effective stress, which enhances the occurrence of earthquakes. Kato et al. (2007) explained the low seismicity by the stabilization of frictional slip by high-pore water pressures as expected by laboratory experiment of rock friction (Scholz, 1998). Normal faulting events found in this study are located in the active cluster adjacent to the SW edge of low seismicity zone in the central section. Compared with the tomographic image by Kato et al. (2007), normal faulting events are distributed in a deep periphery of low $V_{P} / V_{S}$ zone, though the resolution of tomography is not sufficient at their depth. We interpret that these events are caused by local stress heterogeneity in a transition zone from aseismic to seismic stress regime. In fact, these events have small magnitudes and occurred in a short period (Fig. 10(d)). This explains why such earthquakes have not been reported before. To prove the above hypothesis a dense temporary seismic network should be deployed in the active cluster area. Accordingly more focal mechanism solutions will be determined accurately, which leads to the improved spatial resolution of the stress tensor inversion.

From the comparison with tomographic studies we interpret that both strike-slip events apart from the Atotsugawa fault and normal faulting events in the central section of fault imply the effect of crustal fluids to the stress field. In particular, if the mid crustal low $V_{P} / V_{S}$ and the low $V_{P}$ zone in the central section is due to the intruded fluid as inferred by Kato et al. (2007), the fluid also plays dramatic role to change the stress field extensional in the deep portion of fault. Thus the close examination of focal mechanisms helps to investigate the existence and effect of crustal fluids to the seismogenic processes.

\section{Conclusions}

High quality 151 focal mechanism solutions were determined by using a $P$-wave first motion polarity data observed between January 2005 and December 2006 by a dense temporary seismic network in the Atotsugawa fault area, central Japan. The feature of spatial distribution of focal mechanisms is characterized by a uniform direction of $P$-axis while the faulting type is variable; predominant strike-slip events are distributed widely while minor reverse- and normal-faulting events are located to the northwest and near the center of fault, respectively. Using the obtained focal mechanism data we applied a stress tensor inversion method to invert for stress field along and around the fault. We found that the orientation of the inverted $\sigma_{1}$ and $\sigma_{3}$ stress tensors is consistent with the known regional stress field. The angle is $\sim 45^{\circ}$ between the Atotsugawa fault and the $\sigma_{1}$ axis, indicating that the fault is not weak. The stress field shows local perturbation along the fault. We found some normal-fault type earthquakes in the active cluster at the central part of Atotsugawa fault, however, the duration of their activity was short. The stress tensor inversion shows local extensional field in the deep part (depth $>$ $8 \mathrm{~km}$ ) adjacent to low $V_{P}$ and low $V_{P} / V_{S}$ zone imaged by tomographic study. We suggest that the extensional stress is caused locally in a transition zone from the fluid-rich aseismic zone to the seismogenic zone.

Acknowledgments. To determine focal mechanism solutions we used a program HASH produced by Hardebeck and Shearer (2002). To conduct a stress tensor inversion we used a program SATSI developed by Hardebeck and Michael (2006). GMT (Wessel and Smith, 1991) was used to make figures. The comments of two anonymous reviewers are useful to improve the manuscript. This research was supported by "The 2nd New Program for Earthquake Prediction Research and Observation" of Ministry of Education, Culture, Sports, Science and Technology of Japan (MEXT).

\section{References}

Crampin, S., The fracture criticality of crustal rocks, Geophys. J. Int., 118, 428-438, 1994.

Crampin, S. and S. Peacock, A review of shear-wave splitting in the compliant crack-critical anisotropic Earth, Wave Motion, 41, 59-77, 2005.

Geographical Survey Institute, Crustal movements in the Chubu and Hokuriku districts, Rep. Coordinating Committee Earthq. Pred., 63, 316-322, 2000.

Hardebeck, J. L. and A. J. Michael, Stress orientations at intermediate angles to the San Andreas Fault, California, J. Geophys. Res., 109, B11303, doi:10.1029/2004JB003239, 2004.

Hardebeck, J. L. and A. J. Michael, Damped regional-scale stress inversions: Methodology and examples for southern California and the Coalinga aftershock sequence, J. Geophys. Res., 111, B11310, doi:10.1029/2005JB004144, 2006.

Hardebeck, J. L. and P. M. Shearer, A new method for determining firstmotion focal mechanisms, Bull. Seismol. Soc. Am., 92, 2264-2276, 2002.

Hirata, N. and M. Matsu'ura, Maximum-likelihood estimation of hypocenter with origin time eliminated using nonlinear inversion technique, Phys. Earth Planet. Inter., 47, 50-61, 1987.

Iidaka, T., T. Iwasaki, T. Takeda, T. Moriya, I. Kumakawa, E. Kurashimo, T. Kawamura, F. Yamazaki, K. Koike, and G. Aoki, Configuration of subducting Philippine Sea plate and crustal structure in the central Japan region, Geophys. Res. Lett., 30, 1219, doi:10.1029/2002GL016517, 2003.

Ito, K., Seismic activity and tectonics in southwestern Japan, Zisin 2, 43, 555-569, 1990 (in Japanese with English abstract).

Ito, K. and H. Wada, Observation of microearthquakes in the Atotsugawa 
fault region, central Honshu, Japan, in Seismogenic Process Monitoring, edited by H. Ogasawara, T. Yanagidani, and M. Ando, pp. 229-243, A. A. Balkema Publishers, 2002.

Ito, K., T. Ueno, H. Wada, S. Ohmi, and K. Yoshii, Detailed distribution of earthquakes and crustal structure in the Atotsugawa fault area, Ann. Disas. Prev. Res. Inst., Kyoto Univ., No. 46B, 681-690, 2003 (in Japanese with English abstract).

Japanese University Group of the Joint Seismic Observations at NKTZ, The Japanese University Joint Seismic Observations at the Niigata Kobe tectonic zone, Bull. Earthquake Res. Inst. Univ. Tokyo, 80, 133-147, 2005.

Kato, A., E. Kurashimo, N. Hirata, T. Iwasaki, and T. Iidaka, Imaging crustal structure around the western segment of the Atotsugawa fault system, central Japan, Geophys. Res. Lett., 33, L09307, doi:10. 1029/2006GL025841, 2006.

Kato, A., T. Iidaka, E. Kurashimo, S. Nakagawa, N. Hirata, and T. Iwasaki, Delineation of probable asperities on the Atotsugawa fault, central Japan, using a dense temporary seismic network, Geophys. Res. Lett., 34, L09318, doi:10.1029/2007GL029604, 2007.

Koizumi, M., K. Ito, and H. Wada, Focal mechnanisms in the northwestern Chubu district, central Honshu, Japan, Ann. Disas. Prev. Res. Inst., Kyoto Univ., No. 36B-1, 305-324, 1993 (in Japanese with English abstract).

Michael, A. J., Use of focal mechanisms to determine stress: A control study, J. Geophys. Res., 92, 357-368, 1987.

Mikumo, T., M. Koizumi, and H. Wada, Seismicity, focal mechanism, and tectonics in the northern Hida region, central Japan, Zisin 2, 38, 25-40, 1985 (in Japanese with English abstract).

Mikumo, T., H. Wada, and M. Koizumi, Seismotectonics of the Hida region, central Honshu, Japan, Tectonophysics, 147, 95-119, 1988.

Mizuno, T., H. Ito, Y. Kuwahara, K. Imanishi, and T. Takeda, Spatial variation of shear-wave splitting across an active fault and its implication for stress accumulation mechanism of inland earthquakes: The Atotsugawa fault case, Geophys. Res. Lett., 32, L20305, doi:10.1029/2005GL023875, 2005.

Nakajima, J. and A. Hasegawa, Deep crustal structure along the NiigataKobe Tectonic Zone, Japan: Its origin and segmentation, Earth Planets Space, 59, e5-e8, 2007.

Sagiya, T., S. Miyazaki, and T. Tada, Continuous GPS array and presentday crustal deformation of Japan, Pure Appl. Geophys., 157, 2303-
2322, 2000 .

Scholz, C. H., Earthquakes and friction laws, Nature, 391, 37-42, 1998.

Scholz, C. H., Evidence for a strong San Andreas Fault, Geology, 28, 163 166, 2000.

Townend, J. and M. D. Zoback, Implications of earthquake focal mechanisms for the frictional strength of the San Andreas fault system, in The Nature and Tectonic Significance of Fault Zone Weakning, edited by R. E. Holdsworth, R. A. Strachan, J. F. Magloghlin, and R. J. Knipe, pp. 13-21, Geol. Soc. London Spec. Publ., 186, 2001.

Townend, J. and M. D. Zoback, Stress, strain, and mountain building in central Japan, J. Geophys. Res., 111, B03411, doi:10. 1029/2005JB003759, 2006.

Tsukahara, H. and Y. Kobayashi, Crustal stress in the central and western parts of Honshu, Japan, Zisin 2, 44, 221-231, 1991 (in Japanese with English abstract).

Wada, H. and K. Ito, Seismic activity in the vicinity of the Atotsugawa fault, Ann. Disas. Prev. Res. Inst., Kyoto Univ., No. 38B-1, 235-250, 1995 (in Japanese with English abstract).

Wada, H., K. Ito, S. Ohmi, M. Koizumi, and N. Hirano, Observation of earthquakes by a dense station network in the Atotsugawa fault zone, central Honshu, Japan, Ann. Disas. Prev. Res. Inst., Kyoto Univ., No. 44B-1, 229-236, 2001 (in Japanese with English abstract).

Wada, H., K. Ito, S. Ohmi, and N. Hirano, Ultra-microearthquake activity in the Hida region, central Japan, Ann. Disas. Prev. Res. Inst., Kyoto Univ., No. 46B, 671-680, 2003 (in Japanese with English abstract).

Watanabe, T., The influence of a surface sedimentary layer on the crustal stress-An application to regional variation of fault type from Hida to Toyama and Noto, Bull. Earthq. Res. Inst. Univ. Tokyo, 83, 243-249, 2008 (in Japanese with English abstract).

Wessel, P. and W. H. F. Smith, Free software helps map and display data, EOS Trans. AGU, 72, 445-446, 1991.

Yamamoto, K., N. Sato, and Y. Yabe, Elastic property of damaged zone inferred from in-situ stresses and its role on the shear strength of faults, Earth Planets Space, 54, 1181-1194, 2002.

Zoback, M. D., Strength of the San Andreas, Nature, 405, 31-32, 2000.

K. Katsumata (e-mail: kkatsu@mail.sci.hokudai.ac.jp), M. Kosuga, H. Katao, and the Japanese University Group of the Joint Seismic Observations at NKTZ 